\title{
Architecture of geothermal places: socially and culturally responsive therapeutic landscapes
}

\author{
Jacqueline McIntosh, Bruno Marques \& Kezia Fairbrother
}

To cite this article: Jacqueline McIntosh , Bruno Marques \& Kezia Fairbrother (2020): Architecture of geothermal places: socially and culturally responsive therapeutic landscapes, Journal of Cultural Geography, DOI: 10.1080/08873631.2020.1820682

To link to this article: https://doi.org/10.1080/08873631.2020.1820682

曲 Published online: 25 Sep 2020.

Submit your article to this journal $匚$

Q View related articles $₫$

View Crossmark data $\asymp$ 


\title{
Architecture of geothermal places: socially and culturally responsive therapeutic landscapes
}

\author{
Jacqueline McIntosh (D), Bruno Marques (D) and Kezia Fairbrother \\ School of Architecture, Victoria University of Wellington, Wellington, New Zealand
}

\begin{abstract}
There is increasing recognition that culture plays a crucial role in shaping therapeutic environments; from fundamental conceptions of wellness and healing, through to cultural relationships with the natural world, and to how spaces are shaped by culturally-specific construction methods and materials. This paper approaches the concept of therapeutic landscapes from an architectural perspective, analysing three separate case studies relating to geothermal architecture from the Ring of Fire. It attempts to bridge a gap in the literature regarding geothermal therapeutic landscapes, by understanding these places not purely as 'blue spaces' but rather as socio-cultural encounters which influence material and physical architectural conditions. This paper contributes to our understanding of the role of culture in producing and maintaining architectural places by reflecting on the way in which individuals and groups engage with place, their range of social encounters, experiences, narratives, affective beliefs, and embodiments that combine with architectural materiality and the associated complex culturallyproduced meanings.
\end{abstract}

KEYWORDS Therapeutic landscapes; blue space; culturally responsive landscape architecture; geothermal architecture

\section{Introduction}

Geothermal phenomena have an enduring hold on the human imagination. Geothermal and volcanic tourism have been popular worldwide for centuries (Erfurt-Cooper 2011), and particular phenomena are often attributed with special cultural or spiritual significance. For example, in Aotearoa/New Zealand, the European fascination with geothermal landscapes was first stirred by the magnificent Pink and White Terraces (Figure 1).

Māori (Indigenous) people of that area had long held the nearby Mount Tarawera as highly tapu, or sacred, and had ventured up its slopes only to inter the bodies of important chiefs (Yarwood 2013). When the violent volcanic eruption of Mount Tarawera in 1886 destroyed the famed Terraces and 


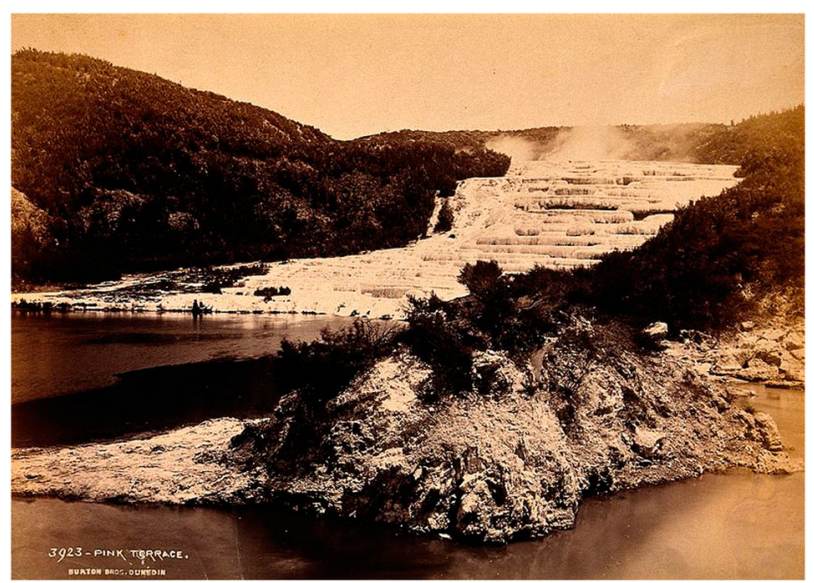

Figure 1. Pink and White Terraces, or Te Tarata (tattooed rock), Waimangu Volcanic Rift Valley, North Island of New Zealand.

devastated the local Mãori population, many local people claimed to have seen a 'ghost waka' (canoe) paddling on the lake earlier that day, in an apparent portent of what was to come. This kind of place-based spirituality is a core part of early research into the concept of therapeutic landscapes, an interdisciplinary frame that seeks to understand places, both natural and architectural, that are perceived to have inherent healing qualities (Bell et al. 2018; Gesler 1992). The literature on geothermally-based therapeutic landscapes, however, has tended to approach them as purely "blue spaces" - effectively centring the water element of the hot spring assemblage. This paper argues that the architecture surrounding hot springs and other geothermal environments can create unique therapeutic landscapes, which need to be considered as more than pure "blue" spaces - that they must be understood equally for their social, cultural and material conditions. An analysis of three culturally distinct case studies is presented in order to better understand how geothermal architecture operates as a therapeutic landscape.

\section{Socially and culturally responsive therapeutic landscapes}

The concept of the therapeutic landscape was originally defined by the geographer William Gesler as a place "where physical and built environments, social conditions and human perceptions combine to produce an atmosphere which is conducive to healing" (Gesler 1996, 96). Over the next two decades, this definition was contested, critiqued and elaborated on. Extending from a literal relationship between health and place with the acknowledgment of extraordinary places to a much expanded and refined characterisation, Williams (2009) organised the definition into six categories of landscape, 
namely: (i) physical places known for health, (ii) applications for healthcare and sites, (iii) spaces of significance for particular populations, (4iv) literary analysis of fiction, (v) use within disciplines outside of geography, and (vi) every day sites of varied therapeutic value. In 2018, the definition of therapeutic landscape was further extended to encompass the promotion of health as well as healing, and to incorporate both aesthetic qualities and the more imperceptible social networks offering a sense of security and inclusion (Bell et al. 2018).

To bring to the forefront the centrality of place as an operational living construct, the new post medical geographies of health looked to the reinvigorated theorisations of place and landscape in cultural geography (Doughty 2018). This theoretical turn saw a much greater emphasis on qualitative and ethnographic methodologies in the study of health designed to reveal the histories, discourses, and lived experiences of the place. In this vein, Conradson (2005) argued that therapeutic landscape experiences should be more critically approached as "relational outcomes", as things that emerge through a complex set of transactions between a person and their broader socioenvironmental setting, bringing together the physiological and the psychological responses to place.

In defining therapeutic environments as reliant on a series of encounters, networks, and associations, Duff (2011) has classified these enabling resources into three categories: social, affective, and material. Social resources are directly linked to place, since they are a product of it and simultaneously enable everyday experiences. These experiences are grounded in relationships established through the enactment of our emotions with therapeutic environments. Affective resources are the fusion of individual or collective feelings that define or restrict orientations or actions. Material resources characterise the way in which relationships are established through the materiality of place and how they impact our access to goods, services, and information. A variety of processes are used to foster social responsiveness in therapeutic environments, bringing together the relational, affective, emotional and cognitive skills that create and maintain social networks and promote meaningful experiences.

Embodied experiences and movement in affective encounters are argued to be related to health and wellbeing in a form of assemblage. Foley and Kistemann (2015) considered therapeutic spaces as emergent through a set of embodied experiential practices linking affects, emotions, and bodily sense that arise from being immersed in such therapeutic environments. This form of assemblage can therefore be better understood through its material, metaphorical, and inhabited dimensions (Foley 2011; Foley, Wheeler, and Kearns 2011). The material component would contain the tangible aspects of landscape that are experienced by people (body and embodiment) due to their therapeutic qualities. The metaphorical component comprises the 
ethnographic and cultural values expressed through narratives, myths, and stories that are crucial in defining site-specific rituals and cure (affect and mind). The last component of inhabitation brings together mind, body, and spirit because it draws from lived, experiential, and performative dimensions of health in place. Building on the contention that different people experience therapeutic landscapes differently or at different times, the potential healing outcome of the landscape can be seen as a relational process, and therapeutic landscapes become socially and culturally responsive. While both of the proposed frameworks by Duff (2011) and Foley (2011) establish the material, metaphorical (or affective), and inhabited (or social) dimensions of therapeutic environments, Andrews (2017) proposed two streams of application. One relates to the impact of landscape on human experience and the other pertains to the application of how therapeutic landscapes are shaped by the influence of different belief systems, leading to the cultural specificity of the therapeutic landscape concept. This extends the therapeutic landscape concept to encompass both tangible and intangible values, supporting the proposition that health, wellbeing, and place are intricately intertwined and emergent through the layering of architecture and material; with practices and responses in a narrative of individual and communal history where people are simply seeking wellbeing.

\section{Blue spaces and geothermal places}

In general, the literature about geothermal places as therapeutic landscapes has focused on the role of hot springs as blue space. Blue space literature focuses on healing places containing significant water elements, distinct from "green spaces" such as forests and parks (Bell et al. 2018; Foley and Kistemann 2015; Völker and Kistemann 2011). Foley and Kistemann (2015) argue that healthy blue spaces are about "health-enabling places and spaces, where water is at the centre of a range of environments with identifiable potential for the promotion of human wellbeing" (157). Brown's critique of this "palette-based" framing of therapeutic landscapes is that it places undue emphasis on the visual aspect of place, at the expense of other sensory conditions (Brown 2017). This is certainly true with respect to geothermal hot springs, where the perceived healing aspects of the water itself is often conditional on other sensory aspects, such as the texture of certain dissolved minerals, or the effect of heat on sore muscles (Stanhope, Weinstein, and Cook 2018). As well as this, the particular cultural conceptions of place and wellness that are associated with geothermal places need to be recognised as a part of their therapeutic assemblage (Wilson 2003). The common "balneological" analysis of hot springs, which centres on the physical properties of hot spring water, leans into a more Western conception of water-health-place which is often at odds with the more holistic Indigenous 
understanding (Foley, Wheeler, and Kearns 2011; Marques, Grabasch, and McIntosh 2018; McIntosh, Marques, and Hatton 2018). Moving away from blue space analysis, this paper takes the more relational approach suggested by Conradson (2005), comparing and contrasting the cultural and architectural elements of three different geothermal places to better understand how therapeutic experiences are derived from these environments. Drawing from the distinction between a therapeutic landscape and a therapeutic landscape experience, this paper sheds light on the importance of social material and cultural configurations and their associated dynamics, within which occur the relationships that shape the individual's sense of self (Conradson 2005).

\section{Selection of case studies and method}

We chose three case studies from around the Pacific Ring of Fire. Since our interest in the topic originates from an Aotearoa/New Zealand perspective, we selected other sites with similar latitudinal ranges in order to find similar climatic conditions in both the Northern and Southern hemispheres. While many countries within this range have active geothermal areas, we selected these case studies primarily for their diverse cultural settings and recent architectural interventions. We analysed the case studies by drawing on a range of primary and secondary material, including site visits by the authors, statements from the architects, owner websites, architectural reviews and books, and journal and news articles.

\section{Case Study 1 - Ginzan Onsen Fujiya, Japan}

The small town of Ginzan lies in Honshu Island's Yamagata Prefecture. Yamagata is a highly active geothermal area, with over 100 hot springs (mainly used for bathing) and rich mineral deposits formed over millennia by the shifting tectonic activity in the zone (Koseki 2010). Thermal water surfaces along the Ginzan River at temperatures of $45-64^{\circ} \mathrm{C}$. As much as the unique mineral properties of the land contribute to the perception of touji (onsen therapy) at Ginzan Onsen, they are also part of the history of human development in the area. Ginzan (literally: Silver Mountain) was originally established as a silver mine, but when the mine ceased production it was reinvented as a hot spring destination. In 2006, architect Kengo Kuma was approached by the family owners of the Fujiya Inn to reconstruct the inn, maintaining the traditional elements of the building while updating its design to reflect modern sensibilities.

Japan has one of the oldest recorded traditions of geothermal utilisation in the world. Japan's onsen (hot spring) culture has both strong historic and contemporary associations with healing. The first recorded onsen was established during the Kamakura period, between 1192 and 1333. Early onsen were famed 
for their healing properties from these early beginnings, and were especially utilised by recovering warriors during periods of war and conflict (Serbulea and Payyappallimana 2012). Ginzan Onsen Fujiya is a 350-year-old inn that sits within one of the country's many onsen towns - towns which, like European spa towns, are dedicated to providing visitors with unique geothermal experiences (Figure 2). Traditional onsen bathing promotes a closeness with nature, through placing pools outdoors (rotenburo), using natural materials and using natural decorative imagery. This likely evolved from Japan's indigenous Shinto religion, which places high value on the natural environment and ritual purification through water, a practice later integrated into Buddhist rituals. Onsen use for therapeutic purposes in Japan has evolved into a more formalised tradition of touji, which is highly regulated and attributes different healing qualities to different kinds of minerals in thermal waters (Nirei, Furuno, and Kusuda 2010; Serbulea and Payyappallimana 2012). As well as thermal water touji, geothermal environments are used for sand, steam, mud, and bedrock bathing therapies which provide various forms of relief for visitors and patients.

The architecture of Kuma's restored inn is a modern reflection of the traditions and cultural conceptions of onsen wellness therapies (Figure 3). Many of the design choices were constrained by the surrounding environmental and built context, such as the design of the facade, which had to fit with its Taishoera neighbours (Pearson 2007), and the size of the site which was dictated by the form of the river valley. On the other hand, working with an historic building meant that certain other restrictions could be circumvented. Normally structures over two storeys in Japan are not allowed to be built from

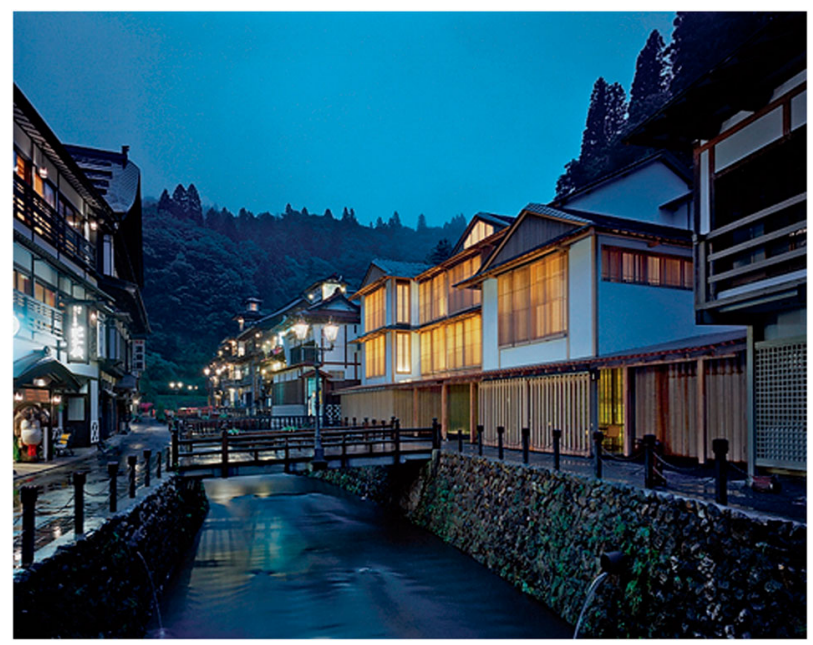

Figure 2. Ginzan Onsen Fujiya from street (Pearson 2007). 


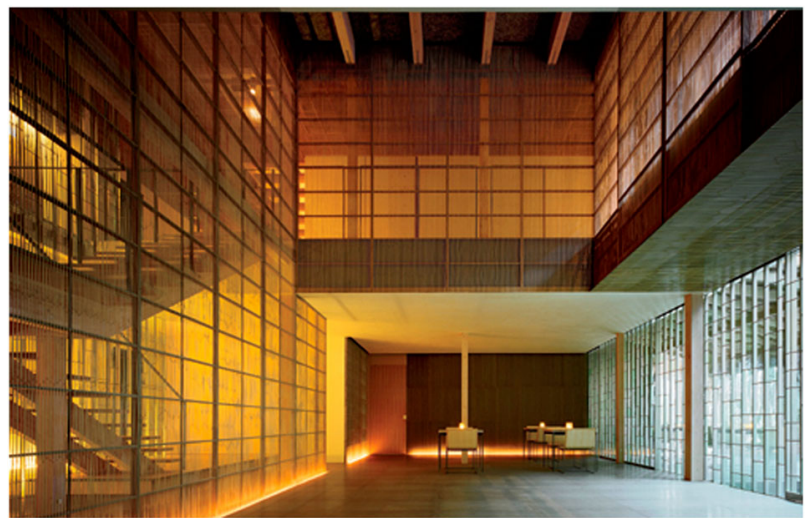

Figure 3. Ginzan Onsen Fujiya interior entranceway (Pearson 2007).

wood, however, the traditional nature of the project meant that exceptions were made to allow the three-storey building to be constructed primarily of timber (Bognar 2009).

Material and detailing are at the heart of the design of the rebuilt inn. The very bones of the new structure are drawn from the old - where possible, elm from the original inn was salvaged and reused. Despite there being no external pools, a strong relationship to the natural environment is engaged through a clever layering of different natural textures and diffusions of lighting, which lead the visitor carefully through a variety of spatial atmospheres until they are ensconced within their carefully screened private rooms, or settled in one of the individually designed private pools. There are two common ways of circulating water through onsen baths in Japan, flow-through and circulated filtration (Nirei, Furuno, and Kusuda 2010). The hot springs at Fujiya are of the first kind, drawing directly on the thermal water sources around the river to feed pools at a constant rate, with overflow channels to allow for a steady renewal of the waters. There are five pools in the complex, with several located on the first floor. Guest rooms are confined to the second and third floors, where more pools can be found. Each pool has its own material quality, whether it be Chinese stone, hiba timber, bamboo, or shoji paper, each of which bring a certain kind of light, smell, and touch to the atmosphere. Each pool is a celebration of the natural qualities of traditional onsen materials, emphasised by carefully placed artificial or natural lighting. The water fed into each pool may be drawn from the same source, but each pool produces its own distinct meditative atmosphere (Edensor 2012) through lighting, material and detailing. The pools of Fujiya are affective atmospheres where the haptic elements of traditional onsen materials are used to enhance the immersive experience of onsen bathing. 
It has been suggested that the well-being effects of onsen therapy are amplified by the environmental and locational factors surrounding onsen (Serbulea and Payyappallimana 2012). The Fujiya inn sits shoulder to shoulder with its neighbours, facing towards the thermal river, which is a central feature of the town. The streets on either side of the water are linked via bridges, and an open public footbath invites people to sit and contemplate the built and natural environment as one. At night, the streets are lit only by gas lamps - engaging on one level a nostalgia for the past, but also reinforcing the connection to the natural cycles of night and day.

Entering Fujiya from such a setting, the visitor passes under a veranda over a short stone walkway. The experience of entry and movement throughout the facility is carefully orchestrated, purposefully designed to engage every sense and to convey symbolic meaning. The inclusion of two shallow pools on either side of this path create the illusion of a bridge in the entrance area. On entry, the visitor passes through a threshold wall composed of glass formed using a 700-year-old technique (dalle de verre). The semi-transparent, mottled nature of this glass softens the natural light entering the space and allows it to blend harmoniously into the warm artificial lighting, which has been carefully placed in recessions that hide the source from view. The lofty entrance area is defined by an abundance of bamboo screens composed of $4 \mathrm{~mm}$ bamboo lengths, stripped by hand, and fixed to wooden frames (Pearson 2007). The transparency of these screens helps to diffuse the internal lighting, while creating a visual "glimpse" of the spaces that lie ahead. The act of entering this place is made significant through the symbolic elements of the bridge, and the spatial contrast of the transitional space - moving from the low external veranda to the high ceilings of the entrance hall. This performative entry space resonates with the Buddhist doctrine of purification, in which movement through space and time is key (Bharne 2014). As in Japanese shrines, the journey of the approach is an important part of the architecture. The use of such spatial and temporal devices harks back to the roots of onsen culture. The internal space of the ryokan (guesthouse) interacts with the external landscape to create a signified spiritual therapeutic experience, where the purification element of onsen bathing is performed not only through interaction with water, but through the body's movement through architectural space.

\section{Case Study 2 - Termas Geométricas, Chile}

While Ginzan Onsen Fujiya sits within a long, unbroken tradition of geothermal utilisation, the second case study is an example of geothermal architecture in the postcolonial context of central Chile. Termas Geométricas is situated near the town of Conaripe, in the Panguipulli commune of the Valdivia province in Chile. Snaking through a steep gorge, deep in the region's Valdivian rainforest, at the base of the Volcán Villarrica, are a number of geometrically- 
shaped natural pools built from natural stone and fed by local thermal springs. Within this remote location, Chilean architect Germán del Sol worked with the local community to create an architecture which encourages emotional connections to both nature and culture (Alvardo, Trebilcock, and Ascui 2007) (Figures 4 and 5).

Before the arrival of the Spanish in the 1500s, Chile was occupied by multiple Indigenous groups, who occupied the land from as early as 600AD. The largest surviving Indigenous group today are the Mapuche ("People of the Land"), an ethnic group that encompasses a wide range of communities, beliefs, and social systems, united by a shared language (Mapudungun). While the Mapuche of northern and southern Chile were quickly conquered by the Spanish, the Mapuche located within the central region of Chile (where Termas Geométricas is located) strongly resisted conquest. For a time, this area of Chile, dividing the north and south, was under Indigenous control and the Spanish wanting to travel between it had to either travel by sea or receive local permission (Crow 2013). The area, sometimes referred to as Araucania, was incorporated fully into Chile following a period of Chilean territorial expansion during the late 1800s. While there is a culture of geothermal utilisation and bathing in Chile, recognisable from the number of natural hot springs and hot spring resorts that can be found there, there is very little reliable English-language information on the history of this development, particularly as it relates to Mapuche. Mapuche have a plant-based traditional medicine overseen by a machi (shaman), which draws on ancestral knowledge and is viewed by its adherents (both Mapuche and non-Mapuche) as being more holistic than Western medicine (Bonnefoy 2015). Given the role of

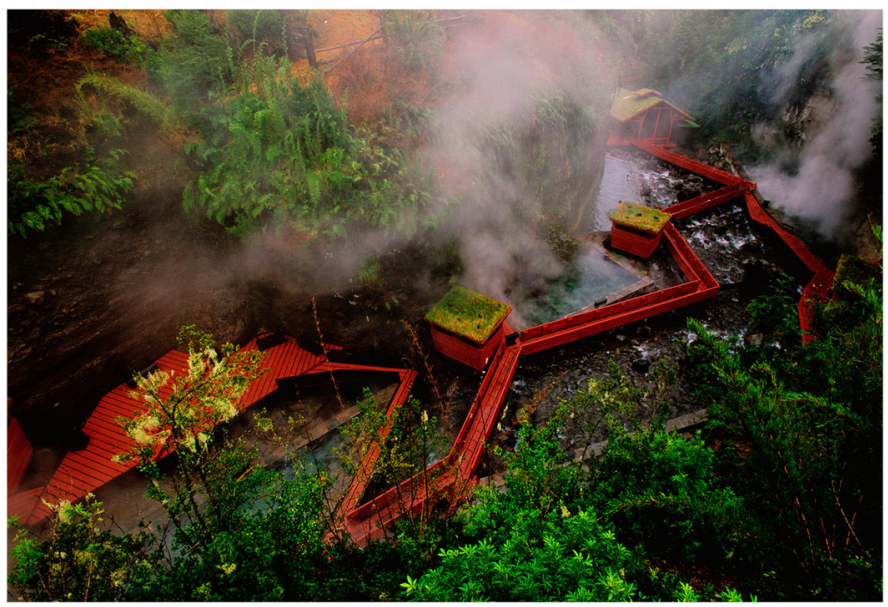

Figure 4. Termas Geometricas follows the landscape (Termas Geométricas de Germán del Sol 2018). 


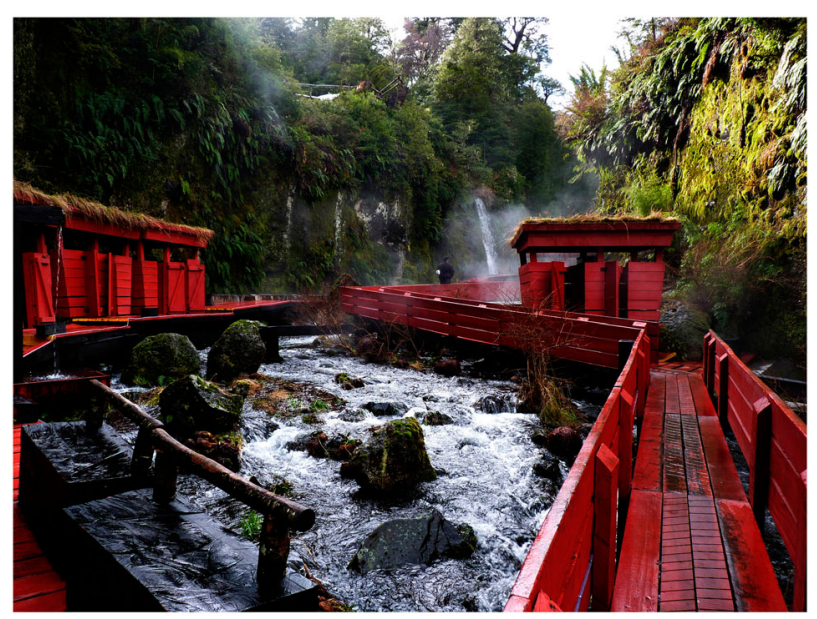

Figure 5. Raised pilotis allow the river to flow freely (Termas Geométricas de Germán del Sol 2018).

heat and steam in this medical practice, it is likely that geothermal resources may have been utilised as part of certain treatments, but more research is needed to understand on a more detailed level the role of geothermal environments in Mapuche conceptions of wellness.

Architect Germán del Sol set about developing the Cajon Negro gorge in the 1990s, after many years of involvement in the tourism sector in Chile, which included many projects involving Indigenous communities (Hernández 2010). Following early settler accounts of "mystical sites", del Sol discovered the site and leased the land for a 30-year period from one of the few remaining forestry haciendas (colonial estates) in the Villarica National Park (Martignoni 2006). The site is a $500 \mathrm{~m}$-long, stone-faced gorge near the base of one of Chile's most active volcanos, Volcán Villarrica, which erupted most recently in 2015. The volcano is affected by a fault line system, the path of which is followed by ascending thermal fluids which manifest in the thermal hot spring area. Surface temperatures of thermal reservoirs in this area range from $80^{\circ}$ to $90^{\circ} \mathrm{C}$ (Held et al. 2016). At the project's inception, the ravine was full of trunks and branches, hiding several natural thermal springs and a small slow-moving river. The local workforce then spent a year clearing the site by wheelbarrow rather than by machine, in order to preserve the natural beauty of the site (Termas Geométricas de Germán del Sol 2018).

At the outset of the project, del Sol sought primarily to discover the unique characteristics of the place (Alvardo, Trebilcock, and Ascui 2007). The development of geometrically-arranged pools was inspired by a visit to a Greek tomb site, where the contrast between the formal construction elements and natural surroundings helped make sense of the relationship between 
architecture and site (Martignoni 2006). The irregular pools are set into the stone walls of the gorge on one side and bounded on the outer sides by reinforced concrete tiled with locally-sourced stone, laid out in an angular geometry influenced by the site. His discovery of "place" paid as much attention to the local culture as to the natural environment. As with his earlier work on the Puritama Hot Springs in Atacama, del Sol hired a local workforce and investigated Indigenous and local construction methods and design elements (Figure 6). This resulted in many unexpected design features: the central quincho (deep covered veranda) pays homage to the ruka (traditional housing type) - the central structure of Mapuche communities which serves as both as meeting venue as well as a place for healing (Bonnefoy 2015). The furniture is carved from single pieces of wood by local craftsmen, and even the distinctive red and black colour paint used to protect the timber of the structure was inspired by the contrasting geometry on a poncho cacique (chieftain's poncho) (Del Sol 2014) (Figure 7).

The most significant of these design features is the mechanism of water delivery from the source springs to the bathing pools. Given the hot temperature of the thermal waters at the surface, a mechanism was needed to cool the water and transport it to the more than 20 pools along the valley floor. Del Sol took inspiration from local Mapuche farmers, who use wooden conduits to transport water across the land (Del Sol 2014). After some time in cooling pools, the water is fed into a wooden conduit which runs underneath the gently sloping wooden walkway. This system illustrates how a material component can contain the tangible aspects of a therapeutic landscape but also how intangible ethnographic and cultural values can be respected and expressed through narratives and site-specific interventions.

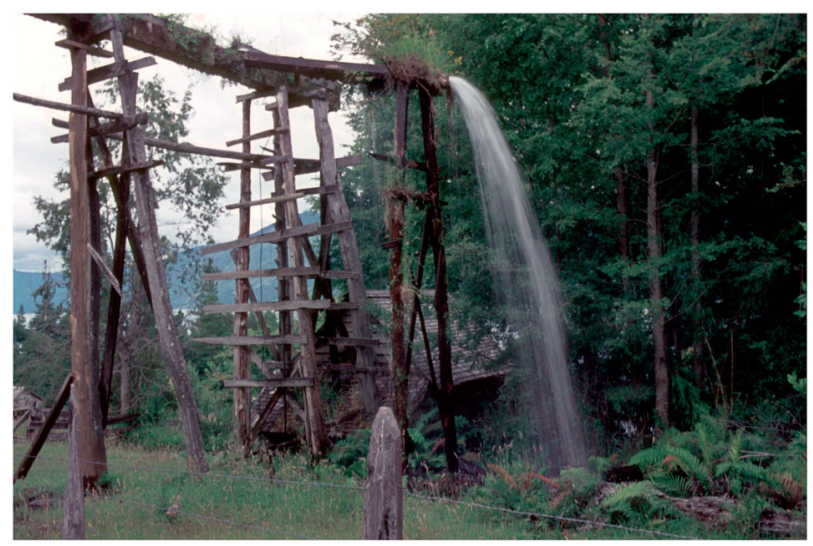

Figure 6. Local agriculture-inspired elements of the architectural design (Del Sol 2014). 


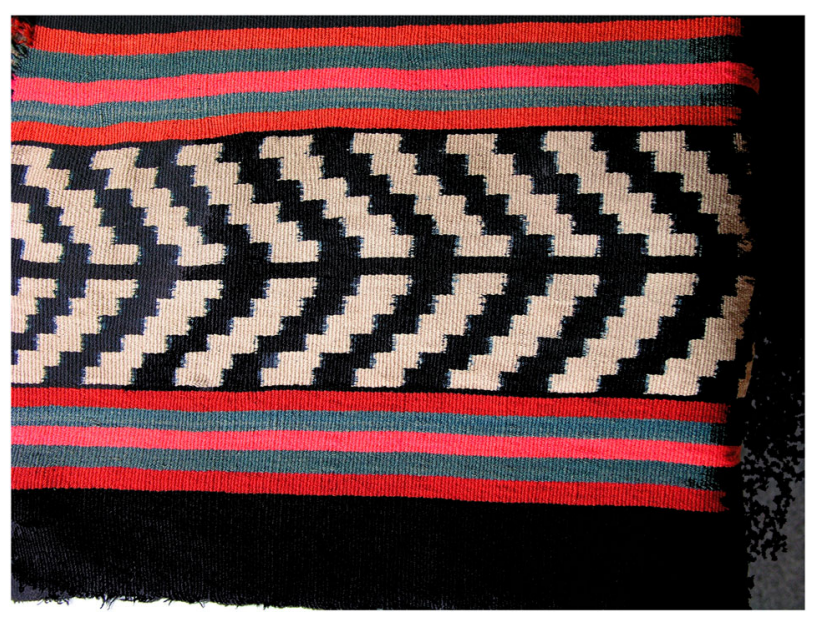

Figure 7. Geometric designs on a poncho cacique (Del Sol 2014).

Each pool draws visitors up the path until they reach the large natural waterfall at the gorge's end. The conduit feeds into each pool, the thermal water cooling as it flows down, so that each pool offers a slightly different temperature. Running a conduit under the walkway has the effect of heating the wooden path, helping to keep it dry and comfortable. Along the way are several smaller huts for changing and toileting, again built from local ciohue timber, with strategically placed gaps to allow for natural ventilation. The roofs of these structures are topped with grass, and the only available lighting is candlelight; the facility utilises only the small amount of electricity generated by a dynamo which is powered by the stream's flow.

The programme emphasises movement through place, asking viewers to stop along the way and appreciate different views of the spectacular natural setting; but not to linger. Many of the pools are often too hot to stay in for long, and there are no obvious gathering points along the way. Picnicking is prohibited, and even the central quincho, the largest structure near the outset of the journey, offers only light meals to encourage shorter stays. As people move up the path towards the waterfall, the water from the river runs down the valley floor, flowing unencumbered around the architectural interventions, as all structures are suspended above the valley floor on wooden pilotis. Movement becomes a key element of the therapeutic assemblage of Termas Geometricas - the flow of water from spring to pool, the flow of the river along the valley floor, the movement of people from one pool to another, interspersed with brief moments of pause at each new place encounter. With this movement, the body is tied with the architecture, the landscape, and the bodies of others, acting on and with each other to produce a performative therapeutic assemblage (Foley 2011). This assemblage is inclusive of 
both the construction process and cultural history of the place. While more research is needed to understand the social effects of del Sol's inclusion of Mapuche workers and their particular perception of this place, it nonetheless is an attempt at a response to nature which contributes to the architectural character and atmosphere of this unique geothermal encounter.

\section{Case Study 3 - Polynesian Spa, New Zealand}

Polynesian Spa is located in Rotorua, a city in the upper North Island of New Zealand. The Indigenous people of the Rotorua District are Te Arawa, a broad collection of Māori iwi (descent groups) which trace their lineage back to the Te Arawa waka (canoe) which brought the first Māori to the area several hundred years ago. At Rotorua, the largest settlement was Ōhinemutu. This settlement was the base of early, Māori-run tourism ventures (O'Malley and Armstrong 2008). After arriving in Ōhinemutu, curious Europeans would travel up to the nearby settlement of Te Wairoa, from where they would be ferried across the lake to Otukapuarangi and Te Tarata. These extraordinary silica landforms at the base of Mount Tarawera became famous in English as the Pink and White Terraces. Māori held their own spiritual beliefs and mythologies around the geothermal phenomena in the region, including those around their origin. It is said that one of the early ancestors who arrived on Te Arawa, Ngantoroirangi, travelled from the coast to the inner island, exploring, creating, and discovering many of the important features of the land along the way. He ended his journey at Mount Tongariro, where he encountered a bitterly cold storm. In danger of perishing, he called to the deities of fire, Te Pupu and Te Hoata, who followed his path to find him, spreading fire wherever they burst through the land along the way (Neilson, Bignall, and Bradshaw 2010). The relationship of Māori to the landscape is thus linked with their very whakapapa (ancestry), a fundamental perception of place which is at odds with the European understanding of land as something to be owned or exploited (Hatton, McIntosh, and Marques 2017; Wilson 2003).

Steam bathing played an important role in nineteenth century Māori physical therapy, according to the observations of local settlers (Figure 8). Mineral and geothermal springs were utilised extensively not only for physical therapy, but also for cooking, washing, recreation, and also as sites of ritual or spiritual significance (Nicholls, Harwood, and Bell 2016). Early European settlers seized the opportunity of utilising the springs as they were likely reminiscent of popular European balneological and tourism practises at the time. The Rotorua region was given an English designation as the Hot Lakes District, after the English Lakes District, and reflects the Pākehā (NZ European) vision of what the area was to become. The growing colonial power enacted legislation which seized control of all significant geothermal land and 


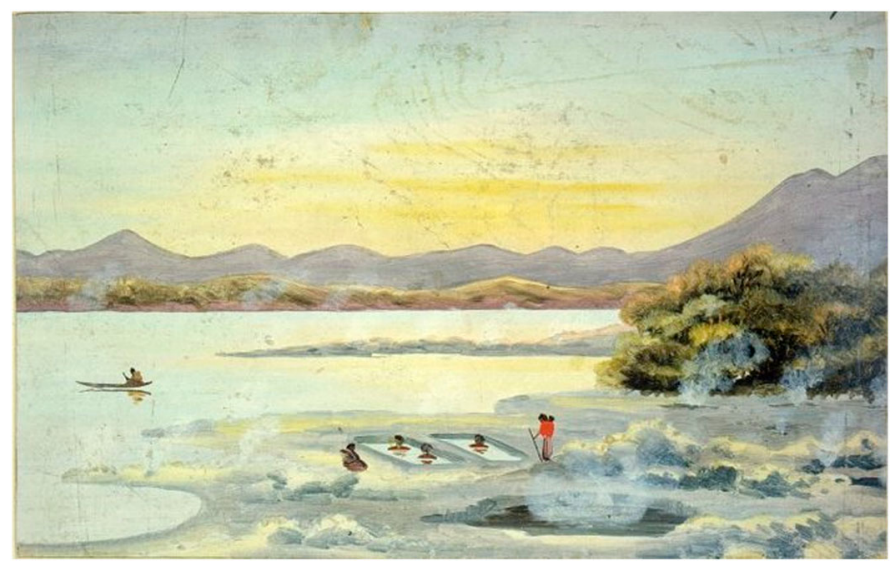

Figure 8. Old Painkiller Bath. Te Kauwhanga Point, Rotorua by John Philemon Backhouse. Oil on board (Backhouse 1880).

criminalised traditional Māori healing practises (O’Malley and Armstrong 2008). After the Mount Tarawera eruption in 1886, which destroyed the Pink and White terraces and devastated the Mãori population, most thermal areas and enterprises were under European control.

Polynesian Spa was first known by Māori as Te Pupunitanga (named after a famous ambush attack between two different iwi of the area). It became famed among Europeans after 1878, when a priest heard rumour of the springs' healing properties and travelled on foot from Tauranga (a nearby city) to bathe in the waters in order to treat his rheumatism. Guided by local Māori, he bathed in Te Pupunitanga, and after a week, he purported to be free of pain and completely cured from his ailment. Following this, Te Pupunitanga became known in English as the Priest's Spring (Rockel 1986). The spring was set into the pumice shoreline of Lake Rotorua and was originally relatively small, reportedly fitting a maximum of four bathers at one time.

In 1882, the Colonial Government began its first attempt at enacting its grand balneological project, which was seen as a way of bringing European tourists to Rotorua (Rockel 1986). The Pavilion Baths were erected on the site, which promptly fell after acidic steam corroded the nails. It was rebuilt in 1887, with a women's bath added in 1896. In 1901, the Duchess Bath was built next door in order to celebrate a visit by the Duchess of York. Both buildings were demolished in 1930 and replaced by the Ward Baths (Rockel 1986). The baths of this era were used both recreationally and medically, providing a range of balneotherapies (Figure 8). There is evidence that the baths were racially segregated, with Europeans objecting to sharing waters with Māori (O'Malley and Armstrong 2008). Contemporary accounts outline 
the plethora of maintenance issues that plagued the baths, including silicaclogged pipes, corrosive acidic steam, mineral build-up on surfaces, and rotting wood. The nearby Rotorua Bathhouse had similar material issues, with hydrogen sulphide in the air staining the lead-based paint used on furnishings black, and with the crumbling of the white plaster used on interior walls (Rockel 1986). These somewhat awkward attempts to frame the natural environment within an architecture that fit European concepts of hygiene, decency, and wellness have been categorised as part of a wider "problematisation of the natural" (Werry 2008). Architecture was utilised to alienate the body from the natural world, which the European worldview at the time equated morally and symbolically with Māori; "wilderness" was contrasted with "civility", European structures represented the future, while Mãori structures were seen as relics of the past.

In 1971, the pools were sold into private ownership (a Pākehā, or nonMãori family), when they were renamed the Polynesian Pools. In the 1990s, the Polynesian Pools became the Polynesian Spa and the existing architecture was adapted to accommodate a range of new pools, catering to tourist interest in spa therapy and balneology (Figure 9). The original structure of the Ward Baths can be seen in the symmetrical pools to either side of the central area, and it is likely that the gabled design of these roofs influenced the design of subsequent additions. Polynesian Spa exists today as a popular resort, with marketing aimed at the wellness tourism market (Polynesian Spa 2018). The complex offers a large range of mineral pools (28 in total), including a range of adult-only pools, private pools (deluxe and standard) and a

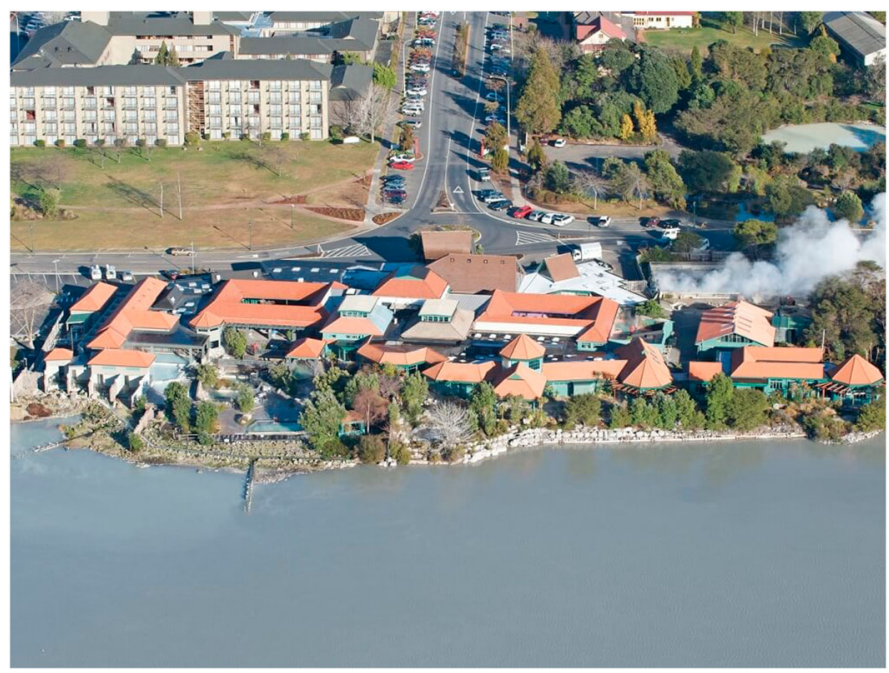

Figure 9. Polynesian Spa today (Polynesian Spa 2018). 
chlorinated family swimming pool with two nearby mineral pools, presumably for parents.

The New Zealand example offers a therapeutic assemblage of a different type. The packaging of the therapeutic landscape experience reflects the power relations in New Zealand's relatively recent history. It capitalises on the reputation of Rotorua as a Maāri geothermal environment to market not only its plethora of different pool types, but also by offering a "European spa retreat" centre, where beauty treatments, cosmetics, massage, and relaxation therapies are offered.

The architecture is equally revealing. The tangible design features of the interior decorations use non-specific, Pacific-inspired design features, such as the large stone pyramid columns that define the entranceway between the cafe and the pools. The intangible narratives sell the Polynesian Spa as a healing environment by invoking both European balneological traditions through its "spa" branding and services, legitimised through an invocation of historical Māori utilisation of the springs (Foley, Wheeler, and Kearns 2011 , 30). Its therapeutic assemblage has evolved out of a particular cultural history in which the geothermal landscape has been a key part of shaping social power and dynamics.

\section{Discussion}

A comparison of the three geothermal environments is useful for a deeper understanding of place and its social context, illuminating aspects of culture. All three sites accommodate both local residents and tourists; albeit in different proportions and from different locations. For, example, in the New Zealand pools, the proportion of international tourists is high, many coming from other geothermal countries. Domestic visitors are more typically tourists from other areas of New Zealand, rather than local residents. In recognition of this, attention is paid to explaining the history of the site and the area. Chilean and New Zealand pools require visitors to wear bathing suits, allow mixed gender bathing and have few restrictions other than those related to health concerns. In contrast, in Japan, cultural rules such as nude bathing, gender separation, prohibition of body tattoos, and cleansing protocols which are enforced by other Japanese users, limit the use of facilities by some international tourists. Unlike in Japan and Chile, in New Zealand clusters of pools can be experienced by different groups: there are private pools available for couples where bathing suits are optional, there are family pools where younger children can join their parents, and there are cooler water pools for more active uses such as swimming.

The therapeutic landscape experience can be enhanced or diminished by the cultural values and social etiquette enacted in the place. For example, in places where it is still socially acceptable to spit, this practice can detract 
from the therapeutic experience of others. In other places, spiritual purification processes can enhance the individual's therapeutic experience by adding a new dimension, expanding the experience beyond the purely phenomenological. Further research is needed into the experiential qualities of geothermal environments, and should be extended to wider geothermal landscapes, beyond those centred on hot springs. Such dynamic natural phenomena naturally inspire spiritual and mythological conceptions of place. These could be better responded to both socially and architecturally if they were better understood as therapeutic landscapes.

In Japan, the experience of bathing is largely contemplative and individual; whereas in Chile and New Zealand, the environment fosters greater intimacy with others. Talking is discouraged in many of the Japanese onsen, as many visitors are solitary, but in Chile the experience is more social, families are commonplace, and strangers are comfortable discussing their experience with others. These environments foster social responsiveness through a variety of processes, interacting with the relational, affective, emotional, and cognitive skills that create and maintain social networks, encouraging trust and promoting intimate relationships.

In Japan, the experience of geothermal bathing forms part of a performative and ritualised cleansing process where bathing in mineral water is only one element of the experience. The narrative of experience is carefully orchestrated from entering the onsen, progressing through stages of cleansing, both physical and spiritual and then on exiting, attention is paid to relaxing and restoration, often with the provision of various body care lotions and products. There are few interventions by service providers such as masseurs, aestheticians, or even gift shops in the onsen; however, many onsen including the one in our case study are linked with full-service hotels and fine dining restaurants. In New Zealand and Chile, the bathing experience is more unregulated, where bathers typically sample a variety of pools, with very limited procedure (showering is recommended before entering the pools, but not enforced) and in no regular order. Café-style eating facilities are typically provided in the hot spring complexes in both Chile and New Zealand, and beauty products and souvenirs are commonly offered for sale.

Material resources include the diverse objects, assets, and benefits that circulate in and through local economic and social networks. While all three case studies are closely linked to nature, the experiences are curated in very different ways. In Japan, there are indoor and outdoor pools. Outdoor views are carefully framed with great attention to showcase the seasonality of the landscape, building materials are mostly meticulously selected and sourced locally, and craftsmanship is of the highest quality and evidenced in every aspect of the onsen. Mineral waters are typically introduced through hidden bore holes and flow continuously through the site to exit into the adjacent landscape. Architectural elements such a bridging, 
transitional space and contrasts of scale are symbolically positioned to offer a potent narrative. In Chile, the nature experience is narrated through the progression along a zig-zagging pathway, nearly a kilometre in length return, with a wide range of different pools, varying in temperatures, sizes, elevations, and vistas. Heated mineral waters are introduced from sources along the sides of the ravine and are cooled through the introduction of varying amounts of fresh cold water from a stream that flows through the site as well as through natural cooling. Vegetation is untamed and the architecture is rustic and rudimentary. Aspects of experience are heightened beyond the natural through the use of device, such as diverting steam underneath the raised pathway, using candles for evening lighting and orchestrating geometries and sight lines. In New Zealand, the resonant feeling of place is captured through expansive views of the geothermal lake, as well as outside pools, some of which are under cover, while others are open. Experience is varied by progression through a series of pools of different in temperatures, sizes, and views. Water does not flow between pools in the Polynesian Spa since waters are treated and recirculated, and refreshed nightly. Natural materials such as stone and wood are used, but are not distinctively from New Zealand nor site-specific. Situated in the historic Mãori tourist town of Rotorua, the New Zealand case study makes connections to European traditions and uses non-specific Pacific inspired design features, hereby illustrating how material resources can illuminate the politics of social power in the dynamics of place.

\section{Conclusion}

A therapeutic environment can hereby be understood as a complex layering of social encounters, cultural objects and performances along with the material traces of embodied occupation. These layers promote a connection between inner meanings and outer contexts while bringing together the lived and experiential dimensions of health and wellbeing in a specific place. Where previously hot springs have been considered in relative isolation from their larger geothermal and cultural contexts, this paper highlights the role of culture and place in the formation of geothermal therapeutic landscapes. By decentring the blue space in these case studies, we begin to see room for different modes of analysis, whether they be sensory, socio-cultural, or otherwise relational. This paper expands on previous literature relating to the concept of therapeutic landscapes in relation to architecture, and presents a new avenue of research in order to better understand how these dynamic landscapes are produced culturally, environmentally, and architecturally.

The therapeutic properties of such places derive from an amalgamation of unique resources; however, such resources are highly variable. In certain 
places, social and affective resources are more prevalent in promoting health encounters, while in other places unique physical and material aspects prevail. This suggests that exploring such dimensions of health and wellbeing can be more challenging than initially anticipated and that places can have diverse effects on the constituencies who inhabit them. One common trace across the different sites explored, is the notion that it is the combination of the tangible and intangible properties of a place that directly affect an individual's health and wellbeing. In the instance of geothermal facilities, experiences are enhanced by the sensuality of the environment and the meanings derived from it. In addition, performative rituals associated with the social and affective encounters of a place might change the experiential dimension of health. Such dynamic phenomena naturally inspire spiritual and mythological conceptions of place. These could be better responded to both socially and architecturally if they were better understood as elements of therapeutic landscapes in an assemblage of meaning.

\section{Disclosure statement}

No potential conflict of interest was reported by the author(s).

\section{Funding}

This work was supported by Health Research Council of New Zealand [grant number E2906].

\section{Notes on contributors}

Jacqueline McIntosh is Senior Lecturer, Victoria University of Wellington, School of Architecture. Her main research interests are design-led culturally-appropriate participatory design for improved health and well-being.

Bruno Marques is Programme Director for Landscape Architecture and Senior Lecturer in Landscape Architecture, Victoria University of Wellington, School of Architecture. His main research interests relate to the integration of Indigenous methods in participatory design in landscape rehabilitation and ecosystem services.

Kezia Fairbrother is Graduate in Architecture, Victoria University of Wellington, School of Architecture. Her research skills and expertise are related to culture, architecture and Kaupapa Māori's subjects in relation to design-led culturally-appropriate architectural design.

\section{ORCID}

Jacqueline McIntosh (D) http://orcid.org/0000-0001-7896-5089

Bruno Marques (iD http://orcid.org/0000-0002-4761-8225 


\section{References}

Alvardo, R. G., M. Trebilcock, and H. Ascui. 2007. "Experiencing the Flows of Nature." Open House International 32 (4): 33-41.

Andrews, G. 2017. "Landscapes of Well-being." In Health Geographies: A Critical Introduction, edited by Tim Brown, Gavin Andrews, Steven Cummins, Beth Greenhough, Daniel Lewis, and Andrew Power, 59-75. Oxford: Wiley-Blackwell.

Backhouse, J. 1880. Old Painkiller Bath. Te Kauwhanga Point, Rotorua. Oil on board. At: National Library of New Zealand. Register number: E-053-004.

Bell, S., R. Foley, F. Houghton, A. Maddrell, and A. Williams. 2018. "From Therapeutic Landscapes to Healthy Spaces, Places and Practices: A Scoping Review." Social Science and Medicine 196: 123-130. doi:10.1016/j.socscimed. 2017.11.035.

Bharne, V. 2014. Zen Spaces and Neon Places: Reflections on Japanese Architecture and Urbanism. China: Applied Research and Design.

Bognar, B. 2009. Material Immaterial: The New Work of Kengo Kuma. 1st ed. New York: Princeton Architectural Press.

Bonnefoy, P. 2015. Alongside a Doctor's Care, a Dose of Traditional Healing [online]. The New York Times. Accessed November 25, 2018 from https://www.nytimes. com/2015/08/20/world/americas/chile-health-care-indigenous-practices-seep-in. html.

Brown, K. M. 2017. “The Haptic Pleasures of Ground-Feel: The Role of Textured Terrain in Motivating Regular Exercise." Health and Place 46: 307-314.

Conradson, D. 2005. "Landscape, Care and the Relational Self: Therapeutic Encounters in Rural England." Health and Place 11 (4): 337-348.

Crow, J. 2013. The Mapuche in Modern Chile: A Cultural History. Gainesville: University Press of Florida.

Del Sol, G. 2014. Termas Geométricas Hot Springs Complex/Germán del Sol [online]. ArchDaily. Accessed December 14, 2019 from https://www.archdaily.com/579931/ termas-geometricas-hot-springs-complex-german-del-sol.

Doughty, K. 2018. “Therapeutic Landscapes." In The Routledge Companion to Landscape Studies, edited by Peter Howard, Ian Thompson, Emma Waterton, and Mick Atha, 341-353. London: Routledge.

Duff, C. 2011. "Networks, Resources and Agencies: On the Character and Production of Enabling Places." Health \& Place 17 (1): 149-156.

Edensor, T. 2012. "Illuminated Atmospheres: Anticipating and Reproducing the Flow of Affective Experience in Blackpool." Environment and Planning D: Society and Space 30 (6): 1103-1122.

Erfurt-Cooper, P. 2011. "Geotourism in Volcanic and Geothermal Environments: Playing with Fire?” Geoheritage 3 (3): 187-193. doi:10.1007/s12371-010-0025-6.

Foley, R. 2011. "Performing Health in Place: The Holy Well as a Therapeutic Assemblage." Health and Place 17 (2): 470-479.

Foley, R., and T. Kistemann. 2015. "Blue Space Geographies: Enabling Health in Place.” Health and Place 35: 157-165. doi:10.1016/j.healthplace.2015.07.003.

Foley, R., A. Wheeler, and R. Kearns. 2011. "Selling the Colonial Spa Town: The Contested Therapeutic Landscapes of Lisdoonvarna and Te Aroha." Irish Geography: Bulletin of the Geographical Society of Ireland 44 (2-3): 151-172.

Gesler, W. 1992. "Therapeutic Landscapes: Medical Issues in Light of the New Cultural Geography.” Social Science and Medicine 34 (7): 735-746. doi:10.1016/ 0277-9536(92)90360-3. 
Gesler, W. 1996. “Lourdes: Healing in a Place of Pilgrimage.” Health \& Place 2 (2): 95105.

Hatton, W., J. McIntosh, and B. Marques. 2017. “Therapeutic Landscapes: The Role of Culture." In Proceedings of the International Conference of Changing Cities III, June 26-30, edited by G. A., 1495-1503. Greece: University of Thessaly.

Held, S., E. Schill, M. Pavez, D. Diaz, D. Morata, and T. Kohl. 2016. "Effects of Major Fault Zones on Geothermal Reservoirs - a Case Study at Villarrica Volcano, Southern Chile." In European Geothermal Congress 2016, September 19-24, 1-5. Strasbourg, France: European Geothermal Energy Council.

Hernández, F. 2010. Beyond Modernist Masters: Contemporary Architecture in Latin America. Berlin: Birkhäuser Verlag AG.

Koseki, T. 2010. "Geothermal Features in Yamagata Prefecture, Northeast Japan.” In Proceedings of the World Geothermal Congress, April 25-29, 1-6. Bali.

Marques, B., G. Grabasch, and J. McIntosh. 2018. "Fostering Landscape Identity Through Participatory Design with Indigenous Cultures of Australia and Aotearoa/New Zealand." Space and Culture, 1-16. https://journals.sagepub.com/ doi/full/10.1177/1206331218783939.

Martignoni, J. 2006. "Hot Spots, Hot Water: The Puritama Hot Springs, The Geometrical Hot Springs, Chile, German Del Sol." Landscape Architecture 96 (8): 92-101.

McIntosh, J., B. Marques, and W. Hatton. 2018. "Indigenous Cultural Knowledge for Therapeutic Landscape Design." In Handbook of Research on Methods and Tools for Assessing Cultural Landscape Adaptation, edited by Isabel de Sousa Rosa, Joana Corte Lopes, Ricardo Ribeiro, and Ana Mendes, 28-52. Hershey: IGI Global.

Neilson, G., G. Bignall, and D. Bradshaw. 2010. "Whakarewarewa a Living Thermal Village-Rotorua, New Zealand.” In Proceedings World Geothermal Congress 2010, 25-29 April 2010, 1-7. Bali.

Nicholls, D., G. Harwood, and R. Bell. 2016. "Physical Therapies in 19th Century Aotearoa/New Zealand: Part 1 - Maori Physical Therapies." New Zealand Journal of Physiotherapy 44 (2): 75-83.

Nirei, H., K. Furuno, and T. Kusuda. 2010. "Medical Geology in Japan.” In Medical Geology. International Year of Planet Earth, edited by O. Selinus, R. Finkelman, and J. Centeno, 329-354. Dordrecht: Springer.

O'Malley, V., and D. Armstrong. 2008. The Beating Heart: A political and socio-economic history of Te Arawa. Rotorua: Huia.

Pearson, C. 2007. “Ginzan Onsen Fujiya.” Architectural Record 159 (9): 122-127.

Polynesian Spa. 2018. About Us [online]. Rotorua, Polynesian Spa. Accessed March 15, 2019 from: https://www.polynesianspa.co.nz/about-us.

Rockel, I. 1986. Taking the Waters: Early Spas in New Zealand. Wellington: Government Printing Office.

Serbulea, M., and U. Payyappallimana. 2012. "Onsen (hot springs) in Japan Transforming Terrain into Healing Landscapes.” Health and Place 18 (6): 13661373.

Stanhope, J., P. Weinstein, and A. Cook. 2018. "Do Natural Spring Waters in Australian and New Zealand Affect Health? A Systematic Review." Journal of Water and Health 16 (1): 1-13.

Termas Geométricas de Germán del Sol. 2018. Diseño + Arquitectura [online]. Accessed November 22, 2018 from: http://www.disenoarquitectura.cl/termasgeometricas-de-german-del-sol/. 
Völker, S., and T. Kistemann. 2011. "The Impact of Blue Space on Human Health and Well-Being - Salutogenic Health Effects of Inland Surface Waters: A Review." International Journal of Hygeine and Environmental Health 214 (6): 449-460. doi:10.1016/j.ijheh.2011.05.001.

Werry, M. 2008. “Tourism, Race and the State of Nature." Cultural Studies 22 (3-4): 391-411.

Williams, A. 2009. “Therapeutic Landscapes as Health Promoting Places.” In A companion to Health and Medical Geography, edited by Tim Brown, Sara McLafferty, and Graham Moon, 207-223. Oxford: Wiley.

Wilson, K. 2003. "Therapeutic Landscapes and First Nations Peoples: An Exploration of Culture, Place and Health." Health \& Place 9: 83-93.

Yarwood, V. 2013. The Night Tarawera Awoke [online]. New Zealand Geographic 65. Accessed December 2, 2018 from https:/www.nzgeo.com/stories/the-nighttarawera-awoke/. 